\title{
Obstructive sleep apnea syndrome and erectile dysfunction: does long term continuous positive airway pressure therapy improve erections?
}

\author{
Tokgoz Husnu ${ }^{1}$, Akyurek Ersoz ${ }^{1}$, Erol Bulent ${ }^{1}$, Ornek Tacettin ${ }^{2}$, \\ Altin Remzi ${ }^{3}$, Akduman Bulent ${ }^{1}$, Mungan Aydin ${ }^{1}$
}

1. Bulent Ecevit University School of Medicine, Departments of Urology

2. Chest Diseases, Zonguldak

3. Namık Kemal University School of Medicine, Department of Chest Diseases, Tekirdağ, Turkey

\begin{abstract}
Objectives: The aim of this age-matched, controlled, prospective clinical study was to investigate frequency and degree of erectile dysfunction (ED) in patients with obstructive sleep apnea syndrome (OSAS) and to evaluate the results of only continuous positive airway pressure (CPAP) therapy on ED in patients with OSAS.

Materials and Methods: A total of 90 patients were evaluated for potential OSAS. They were given an International Index of Erectile Function questionnaire (IIEF) and Beck Depression Inventory. Sixty-two patients with the diagnosis of OSAS were regarded as study group. Twenty-eight patients in whom the OSAS was excluded, were regarded as the control group. Biochemical and hormonal laboratory evaluation were performed. Then all patients underwent a full-night in laboratory polysomnography examination. The degree of OSAS were evaluated by an expert from chest diseases department. Results: When compared to the control group, a decrease in IIEF-5 scores was found in patients with OSAS. However, this decrease was not statistically significant. After 3 months of CPAP usage in patients with mild to moderate and severe degree OSAS, improvement in IIEF-5 scores was statistically significant. Mean value of IIEF-5 score was $16.63 \pm 5.91$ before CPAP and were improved up to $20.92 \pm 6.79(\mathrm{P}=0.001)$.

Conclusion: It is not certainly possible to say that OSAS is clearly associated with ED. However, after 3 months of regular CPAP usage, ED complaints in patients with OSAS might improve positively. Trials with larger series may give more conclusive data.
\end{abstract}

Key Words: Sleep disorder, erectile dysfunction, obstructive sleep apnea syndrome, CPAP

DOI: http://dx.doi.org/10.4314/ahs.v15i1.23

\section{Introduction}

Erectile dysfunction (ED) is defined as the inability to initiate and continue sufficient erection in order to permit satisfactory sexual performance ${ }^{1}$. This situation is connected with both physical and psychosocial health and plays an important role in the quality of life of affected men and their partners. In Turkey, the prevalence of $\mathrm{ED}$ has been reported as $69.2 \%$ in the study that evaluated 1982 men $^{2}$.

\section{Corresponding author: \\ Tokgoz Husnu \\ Bulent Ecevit University School \\ of Medicine, Departments of Urology \\ 67600 Turkey \\ Tel: +90-372-2613075 \\ E-mail: h_tokgoz@hotmail.com}

Obstructive sleep apnea syndrome (OSAS) should be defined as, the recurrent complete (apnea) or partial (hypopnea) episodes of upper respiratory tract obstruction, and it is often characterized by a decrease in blood oxygen saturation ${ }^{3}$. This is one of the most common sleep disorders. The prevalence was considered as 1-5\% for men and 1.2 to $2.5 \%$ for women in the adult population. The prevalence increases with age $e^{4}$. In a study conducted in Turkey, the prevalence of OSAS was found to be as $0.9-1.9 \%{ }^{5}$.

Studies on the patients with OSAS demonstrated that the apneas and hypopneas occuring during the sleep period caused hypoxemia, then hypoxemia caused the activation of the sympathetic nervous system that concomitantly induced cardiovascular system disorders. Consequently, oxidative stress impaired hypothalamic-gonadal axis and lead to psychological depression and decreased libido. In addition, fatigue, decrease in Rapid Eye Movement (REM) sleep period and 
neurogenic dysfunction all provoked the deterioration in the quality of erection ${ }^{6-8}$. So, via above etiologic factors, OSAS may lead to ED in men.

Treatment of patients with OSAS may be classified under five headings, ${ }^{1}$ lifestyle changes, ${ }^{2}$ medical treatment, ${ }^{3}$ surgical treatment, ${ }^{4}$ oral cavity tools and,${ }^{5}$ continous positive airway pressure (CPAP) therapy. Currently, CPAP therapy was regarded as the gold standard treatment. In a study concerning the results of CPAP treatment performed on ED patients with OSAS, Perimenis et al. compared the results of CPAP therapy with combined therapy (CPAP plus sildenafil therapy).

They achieved better results with combined therapy 9 . In our country, in 2008 , a study was performed by Taskin et al. including 17 men with severe OSAS ${ }^{10}$. A statistically significant improvement concerning the IIEF scores after one month of CPAP therapy was noticed. They concluded that the CPAP therapy was effective in the treatment of ED. Recently, Shin et al., evaluated the effects of surgical (uvulopalatopharyngoplasty) and non-surgical approaches (CPAP and mandibular advancement devices) on ED and quality of life in 56 cases with OSAS ${ }^{11}$. Patients were evaluated with the Korean version of IIEF- 5 after treatment However, significant increase in IIEF-5 score was only observed in surgically treated group. In 2013, Budweiser et al. assessed the changes in sexual function in men with OSAS after CPAP therapy ${ }^{12}$. CPAP users $(n=21)$ experienced an improvement in overall sexual function (IIEF-15 summary score) when compared to CPAP non-users $(n=18)$. In contrast to the findings of Shin et al., they concluded that CPAP treatment can improve sexual function.

Similarly, in our study, the frequency of ED in OSAS patients was investigated using control groups. We also formed groups from mild-moderate and severe OSAS cases. In addition, we aimed to evaluate the possible effects of CPAP therapy on IIEF scores. For this purpose, we tried to compare the pre-treatment IIEF scores with post-treatment IIEF scores that were held in third month after treatment.

\section{Materials and methods}

The study was approved by the Research Ethics Board of our University hospital and all patients signed consent forms to participate in the study. Between the period September 2011- June 2012, 90 patients who
In the urology clinic of our hospital, urologists evaluated the ED complaints and possible effects of CPAP treatment. In all cases, a detailed medical and sexual history was taken. The patient's age, presence of erectile dysfunction complaints, the presence of early and late ejaculation, smoking and alcohol consumption, the presence of a systemic diseases, drug use/abuse, physical activity and socio-economic status were questioned and recorded. Detailed physical examination was performed in all patients and the 15-item questionnaire International Index of Erectile Function (IIEF) was completed. IIEF evaluates five domains of sexual function. These are erectile function (6 questions), orgasmic function (2 questions), sexual desire (2 questions), intercourse satisfaction (3 questions), and overall satisfaction (2 questions). Later, a short fiveitem version of the 15-item IIEF was developed (IIEF5) to diagnose the presence and severity of ED. IIEF-5 classifies the ED intensity as mild, moderate or severe.

Beck Depression Scale (BDI) was filled in all men who participated in the study. BDI form consists of 21 questions and commonly used to evaluate the psychological status of the patient. After the diagnosis of OSAS, 28 men were subjected to 3 -month CPAP therapy. At the end of the therapy, IIEF-15 form was also completed.

The thyroid function, fasting blood glucose, total cholesterol, LDL, HDL, triglycerides, and total testosterone tests were all made in all men. Height and weight of all patients were measured and Body Mass Index (BMI) was calculated for each patient. The calculation was made by the formula of BMI $=$ [weight $(\mathrm{kg}) /$ height $(\mathrm{m})^{2}$.

The patients using nitrates, phosphodiesterase type inhibitors and psychotropic medications; patients with hormonal disorders, neuropathic disease, prostate cancer, patients with a history of pelvic trauma, renal transplanted patients, patients with aortic aneurysms, spinal cord injury, penile deformities, alcohol dependence, acute and chronic psychiatric disorders, metabolic and neurological diseases were excluded from the study. tension, stroke, excessive daytime sleepiness, ischemic heart disease, insomnia) and existence of mental disorders $^{13}$

PAP titration was done in an another day for the patients in whom treatment was planned according to the AHI scores. Titration was carried out by an automatic CPAP device (Weinmann, Hamburg, Germany).
The packaged software of SPSS 13.0 was used in the statistical analysis of this study. The Categorical variables in the data set were given with the frequency and percentage, and constant value measurement variables were given together with the average, standard deviation, median, minimum and maximum values. The Compliance of the continous variables with the normal distribution was controlled by the Shapiro Wilk test. One-way variance analysis was used for the comparison of 3 groups with normally distributed variables. Kruskal-Wallis test was used for the comparison of 3 groups with abnormally distributed variables, and Mann-Whitney $\mathrm{U}$ test was used for the comparison of 2 groups. Pearson's Chi-Square test was used for group comparisons of categorical variables. In all analysis, a $\mathrm{p}$ value less than 0.05 was considered as statistically significant.

\section{Results}

According to the results of polysomnography, $90 \mathrm{pa}$ tients with OSAS were divided into 3 groups. Men with an AHI score of less than 5 were regarded as control group ( $\mathrm{n}=28$; Group 1). Men suffering from mild/moderate OSAS were regarded as Group 2 $(n=29)$, while men with severe OSAS were included in Group $3(n=33)$. All men were requested to fill IIEF-5 questionnaire. The CPAP therapy was applied to a total of 28 patients. After 3 months of therapy, they were requested to fill the questionnaire again. Demographic data and clinical parameters for all groups with relevant $\mathrm{p}$ values were given in Table 1. Age groups were simiar in each groups. No statistically significant difference was noticed when the presence of smoking and alcoho use, diabetes mellitus, hypertension, cardiovascular disease and loss of libido were compared between the groups ( $p>0.05$, chi-square test). In addition, no difference was observed when groups were compared in terms of daily physical activity and socioeconomic status. When groups were compared in terms of BDI scores, hormonal (thyroid function tests and serum testosterone levels) and biochemical (total cholesterol, LDL, HDL, triglycerides, fasting blood glucose) parameters, no statistically significant difference was observed ( $\mathrm{p}>0.05$; Kruskal-Wallis test) (Table 1). 
Table 1. Clinical parameters for all groups with relevant $\mathrm{p}$ values

\begin{tabular}{|c|c|c|c|c|}
\hline & Group $1(n=28)$ & Group $2(n=29)$ & Group 3 & $p$ value \\
\hline Age (years)* & $46,07 \pm 12,74$ & $48,97 \pm 11,3$ & $48,85 \pm 10,96$ & $0.569 * *$ \\
\hline BMI $\left(\mathrm{kg} / \mathrm{m}^{2}\right)^{*}$ & $28,92 \pm 4,32$ & $30,10 \pm 4,00$ & $32,14 \pm 3,86$ & $0.522^{* *}$ \\
\hline $\begin{array}{l}\text { Hormonal } \\
\text { parameters* } \\
\text { TSH }(\mu \mathrm{IU} / \\
\mathrm{ml}) \text { free T3 } \\
(\mathrm{ng} / \mathrm{dl}) \text { free } \\
\text { T4 }(\mathrm{ng} / \mathrm{dl}) \\
\text { total testosteron }(\mathrm{pmol} / \mathrm{lt})\end{array}$ & $\begin{array}{c}1,29 \pm 0,7 \\
2 \\
3,69 \pm 0,7 \\
8 \\
1,12 \pm 0,18 \\
327,57 \pm 92,16\end{array}$ & $\begin{array}{c}1,24 \pm 0,6 \\
9 \\
3,64 \pm 0,7 \\
8 \\
1,07 \pm 0,19 \\
312,03 \pm 69,33\end{array}$ & $\begin{array}{c}1,36 \pm 0,8 \\
0 \\
3,82 \pm 0,9 \\
0 \\
1,02 \pm 0,19 \\
292,58 \pm 73,82\end{array}$ & $p>0.05 \dagger$ \\
\hline $\begin{array}{ccc}\text { Diabetes } & \text { Mellitus } & \text { Present } \\
& & \text { Absent }\end{array}$ & $\begin{array}{r}4 \\
24\end{array}$ & $\begin{array}{r}4 \\
25\end{array}$ & $\begin{array}{l}5 \\
28\end{array}$ & $0.988 \ddagger$ \\
\hline $\begin{array}{cr}\text { Hypertension } & \text { Present } \\
& \text { Absent } \\
\end{array}$ & $\begin{array}{r}9 \\
19 \\
\end{array}$ & $\begin{array}{l}10 \\
19 \\
\end{array}$ & $\begin{array}{r}7 \\
26 \\
\end{array}$ & $0.455 \ddagger$ \\
\hline $\begin{array}{c}\text { Cardiovascular disease Present } \\
\text { Absent }\end{array}$ & $\begin{array}{r}2 \\
26\end{array}$ & $\begin{array}{l}2 \\
27\end{array}$ & $\begin{array}{l}1 \\
32\end{array}$ & $0.707 \ddagger$ \\
\hline $\begin{array}{cr}\text { Smoking } & \text { Present } \\
& \text { Absent } \\
\end{array}$ & $\begin{array}{l}17 \\
11\end{array}$ & $\begin{array}{l}13 \\
16\end{array}$ & $\begin{array}{l}18 \\
15\end{array}$ & $0.477 \ddagger$ \\
\hline $\begin{array}{l}\text { Alcohol consumption } \\
\text { Present } \\
\qquad \text { Absent }\end{array}$ & $\begin{array}{l}11 \\
17\end{array}$ & $\begin{array}{l}11 \\
18\end{array}$ & $\begin{array}{l}13 \\
20\end{array}$ & $1.00 \ddagger$ \\
\hline BDI score* & $8,71 \pm 7,35$ & $9,17 \pm 6,30$ & $12,52 \pm 9,89$ & $0.204 \dagger$ \\
\hline IIEF-5 score* & $23,46 \pm 5,27$ & $21,82 \pm 6,05$ & $19,90 \pm 7,05$ & $0.085 \dagger$ \\
\hline $\begin{array}{l}\text { *Values are presented as means } \pm \text { stan } \\
\text { ** One-way ANOV A } \\
+ \text { Kruskal Wallis test } \\
\text { I Chi-square test } \\
\text { IIEF: International Index of Erectile } \\
\text { BDI: Beck Depression Scale } \\
\text { TSH: Thyroid stimulating hormone } \\
\text { BMI: Body Mass Index }\end{array}$ & $\begin{array}{l}\text { dard deviations anc } \\
\text { Function }\end{array}$ & & & \\
\hline
\end{tabular}

No correlation was observed between BMI and IIEF-5 IIEF-5 scores after 3-month CPAP therapy and relescores $(p=0,148, r=0.154)$. When the patients were vant $p$ values were given in Table 2 . assessed on the basis of IIEF-5 scores, changes in
Table 2: Changes in IIEF-5 scores in 28 men who were treated with 3-month CPAP therapy

\begin{tabular}{|c|c|c|c|}
\hline & $\begin{array}{l}\text { Pre-treatment } \\
\text { IIEF-5 score }\end{array}$ & $\begin{array}{l}\text { Post-treatment } \\
\text { IIEF-5 score }\end{array}$ & $\mathrm{p}^{*}$ value \\
\hline Group $2(n=11)$ & $\begin{array}{l}16,45 \pm 5, \\
37 \\
\text { (median: }\end{array}$ & $\begin{array}{l}20,54 \pm 5,8 \\
0 \\
\text { (median: }\end{array}$ & 0.005 \\
\hline Group $3(n=17)$ & $\begin{array}{l}16,76 \pm 6,29 \\
\text { (median:19) }\end{array}$ & $\begin{array}{l}21,17 \pm 7,53 \\
\text { (median:24) }\end{array}$ & 0.001 \\
\hline Total $(n=28)$ & $\begin{array}{l}16,63 \pm 5,91 \\
\text { (median:19) }\end{array}$ & $\begin{array}{l}20,92 \pm 6,79 \\
\text { (median:23,5) }\end{array}$ & 0.001 \\
\hline
\end{tabular}

As seen in Table 3, we observed that the mean min- ave oxygen saturation values $\leq 89 \%$ ( $\mathrm{n}=19$; mean IIEFimum (min) and average (ave) oxygen saturation val- 5 score $=17,89 \pm 7,89)$ and above $89 \%(\mathrm{n}=43$; mean ues in each groups were sionificantly different between score $=22,09 \pm 5,60)$; statistically significant difference each group ( $p=0.001$, Mann-Whitney $U$ test). When in terms of IIEF-5 scores were noticed ( $p=0.049$; the patients were classified into 2 groups according to Mann-Whitney $U$ test).

\section{Table 3: Minimum (Min) and Average (Ave) oxygen saturation values according to groups}

\begin{tabular}{|c|c|c|c|}
\hline & Min O2 saturation & Ave $\mathrm{O}_{2}$ saturation (\%) & $\mathrm{p}^{*}$ value \\
\hline Group 1 & $\begin{array}{l}89,75 \pm 3,02 \\
\text { (median:90) }\end{array}$ & $93,92 \pm 1,51$ (median:94) & \multirow{4}{*}{0.001} \\
\hline Group 2 & \begin{tabular}{|l|}
$83,17 \pm 4,30$ \\
(median:83)
\end{tabular} & $92,20 \pm 1,89$ (median:92) & \\
\hline Group 3 & \begin{tabular}{|l}
$71,81 \pm 12,08$ \\
(median: 75$)$
\end{tabular} & $88,90 \pm 3,16$ (median:89) & \\
\hline Total & \begin{tabular}{|l|}
$81,05 \pm 10,86$ \\
(median:84)
\end{tabular} & 91,53 $\pm 3,15$ (median:92) & \\
\hline
\end{tabular}

* Mann Whitney U test

The average AHI in groups 1,2 and 3 were $2.72 \pm$ which is one of the most important reasons for ED as 1.43 (median value: 2.72 ); $19.84 \pm 5.66$ (median value: well. Also, in only a few studies, the change in erectile $20.90)$ and, $58.71 \pm 19.48$ (median value: 52 ), respec- function after CPAP treatment in OSAS cases were tively. A weak negative correlation between AHI searched. Our main aim in this prospective study and IIEF-5 scores were documented in correlation was to compare the relation between ED and OSAS in analysis $(\mathrm{p}=0.013, \mathrm{r}=0.262)$. a selective group of patients.

\section{Discussion}

CPAP therapy is regarded as the gold standard treatment by pulmonologists in OSAS treatment ${ }^{19}$. We startVarious studies searched the relation between ED ed 3-month-CPAP therapy in 28 OSAS cases with cerand OSAS since $1970 \mathrm{~s}^{14-18}$. However, very few of tain indications (AHI $\geq 15 /$ hour or AHI $\geq 5$ plus these studies examined simultaneously depression the presence of major/obvious symptoms, cardiovas- 
cular or cerebrovascular risk factors and existence of mental disorders). We preferred 3-month therapy, because; after literature review, we concluded that the optimum duration for clinical improvement was defined as 3 months $^{20,21}$

IIEF-5 scores were compared. Although, the $\mathrm{p}$ value was insignificant among groups, there were a tendency to lower IIEF-5 scores when the OSAS severity degree increased (Table 1). So, for us, it is not possible to say that OSAS severity is a strong determinant for $\mathrm{ED}$.

In 2005, Gonçalves et al. examined erectile function For today, age is regarded as the most important deterin patients with OSAS who received CPAP treatent for a period of one month ${ }^{22}$. They evaluated 98 patients and, found out that ED in patients with OSAS was related with nocturnal hypoxemia. In our study, nocturnal hypoxemia has been searched similarly with oxygen saturation values measured all through the night. When the cut-off value for average oxygen saturation values was taken as $89 \%$ for nocturnal hypoxemia; mean IIEF5 scores of patients with nocturnal hypoxemia were statistically significantly lower than those of patients without nocturnal hypoxemia. We think that, recurren apnea attacks in patients with OSAS cause hypoxia reperfusion injury and oxidative stress, release of oxygen radicals and endothelial-derived nitric acid and disruptions in its function concomitantly. So, via the effect on $\mathrm{NO}$ pathway, nocturnal hypoxemia may cause $\mathrm{ED}^{23}$.

Depression is the most important psychiatric disorde that may cause ED in patients with OSAS. No statistically significant difference was determined in terms of BDI among patient groups. Similarly, when control and study groups were compared, no statistical significancy was documented. So, we think that inter-group variabilities in terms of BDI scores were minimized. For example, if we had a group with a significantly higher BDI score; IIEF score for that group would probably be affected, and this would be a limiting factor in the evaluation of the relation between ED and OSAS. Because depression is a major risk factor for ED

One of the most extensive prevalence studies searching the relation between ED and OSAS is the one conducted by Andersen et a ${ }^{24}$. Totally 467 men ranging in age from 20 to 80 have been included in this epidemiological study. When parameters that could effect ED were examined with logistic regression model, they observed that obesity (odds ratio $=1.8$ ), low testosterone level (odds ratio $=4.28)$, disrupted life quality (odds ratio:4.4), AHI over 15 (odds ratio $=2.75$ ) and OSAS diagnosis (odds ratio $=2.13$ ) were predictive for $\mathrm{ED}$. In current study, no statistically significant difference was determined between study groups when the average minant in ED etiopathogenesis. Odds ratio for age was 21,65 in the study conducted by Andersen et al ${ }^{24}$. Thi means that men over 50 have approximately 21 times higher risk for ED than those men in ages between 2030 . Since our study was age matched, in our study, we were able to eliminate the most important determinant in ED etiology.

When the current literature was reviewed, there were also studies which showed no relation between OSAS and $\mathrm{ED}^{18,25,26}$. Schiavi et al. investigated nocturnal penile tumescence in 70 men with polysomnographic study that lasted all through the night for four days and found ho relation between sleep apnea and $\mathrm{ED}^{26}$. In addition, 285 men with ED were examined in a study conducted by Seftal et al. A survey searching OSAS risk factors was made with those patients. According to the results of this study; despite various sleep disorders were determined in patients with ED, no correlation regarding the relation between OSAS and ED was found ${ }^{27}$. However it should be kept in mind that, OSAS investigation was based on a survey and, no polysomnographic evaluation was made in this study. Later, Margel et al., examined 209 patients similarly through sleep questioning survey and IIEF questionnaire, and all patients were subjected to polysomnographic evaluation ${ }^{28}$. They determined decrease in IIEF scores in patients with OSAS, however this decrease was not statistically significant. They determined statistically significant IIEF decrease only in patients with severe OSAS. In contras with the findings of Margel et al., in our study, average IIEF-5 scores in men with severe OSAS (group 3) were not significantly different from group 1 and group 2 However, there was a tendency to decrease in IIEF5 scores when the OSAS severity increased.

Nasal CPAP treatment is effective in patients with OSAS. An interesting study was carried out by Perimenis et al..$^{29}$. In this study, patients with OSAS and ED who received - only CPAP- treatment were compared with -sildenafil plus CPAP- treatment. They found that sildenafil treatment administered together with CPAP is more effective than-only CPAP- treatment. I gree in patients with severe sleep apnea was also investigated by Taskin et al., and possible benefits of CPAP treatment on ED were searched ${ }^{10}$. Fourty patients with severe OSAS were randomized into 2 treatment groups. While men in the first group were treated with CPAP therapy, men in the second group were treated with antidepressant medication for one month. Mean IIEF5 score reached 19.06 from 15.71 in the first group, and this increase was statistically significant. We evaluated men with OSAS after "3-month" CPAP treatment. We believed that "1-month" CPAP treatment would not be sufficient for clinical improvement in ED. As seen in Table 2, mean IIEF-5 score, which was 16.45 before CPAP treatment, reached to 20.54 after treatment of patients with mild-moderate OSAS (group 2) $(\mathrm{p}=0.005)$ When the patients with severe OSAS were examined, the average IIEF-5 score increased up to 21.17 which was 16.70 before the treatment $(p=0.001)$. Taskin and colleagues examined patients with severe OSAS only In addition, we also examined men with mild-moderate OSAS. According to the results of our study, we can say that, men with mild or moderate OSAS may also benefit from 3-month-CPAP treatment as patients with severe OSAS.

In our opinion, if men with OSAS suffer from ED, CPAP treatment should be effective. CPAP therapy combined with oral sildenafil treatment may even be more beneficial as Perimenis et al. previously suggested 29. On contrary to this opinion, 60 patients with OSAS were treated with CPAP in a study carried out by Margel et al. and long term effects of this treatment were searched. Interestingly, IIEF-5 scores decreased after CPAP treatment $t^{30}$. In other words, they concluded that CPAP treatment may disrupt erectile function instead of improving. But, as Taskin et al. already implied in their articles, we think that, CPAP treatment was not administered sufficiently in this study. Margel et al. just administered "one hour CPAP treat ment in a week". However, in our study, CPAP therapy was administered "every night for 3 months". We believe that, intensive CPAP treatment is necessary especially in patients with severe OSAS in order to decrease ED complaints.

Both total and free testosterone levels were lower in patients with OSAS according to the results of the study that was carried out by Gambineri et $\mathrm{al}^{31}$. In contrast, no statistically significant difference was determined in terms of total testosterone among groups our study (Table 1). Thus, current study data does ot support the hypothesis that OSAS decreases the serum testosterone level.

Several limitations of the present study should be concerned. Although, all polysomnographic measurements and evaluations were made by the same pulmonoloists (TO.R.A.) who were blinded to the IIEF result and erectile capacity of men in the study groups, the evaluation of erectile dysfunction and depression via IIEF and BDI questionnaires still remain subjective assessment modalities. But, for today, IIEF is regarded as a widely used, multi-dimensional self-report instrument for the evaluation of male sexual function and, is accepted as the "gold-standard" measure for efficacy assessment in clinical trials of $\mathrm{ED}^{32}$. Same is true for the BDI questionnaire ${ }^{33}$. Secondly, our sample size is not large enough to make a discrete conclusion. Unfortunately, to the best of our knowledge, no prospective, randomized age-matched clinical trial with larger series has been published evaluating the results of CPAP therapy on ED in patients with OSAS. Further studies focused on this subject may give more conclusive data.

\section{Conclusion}

OSAS is not clearly associated with ED. However, after 3 months of regular CPAP usage, ED complaints in patients with OSAS improve positively. Oxygen saturation measurements throughout the night, which was one of the most important tests searching nocturnal hypoxemia, may reveal how much the patient remained hypoxic during the night. In current study, mean IIEF5 scores were lower in men with nocturnal hypoxemia.

\section{References}

NIH Consensus Conference. Impotence. NIH Consensus Development Panel on Impotence. JAMA 1993; 270: 83-90.

2. Akkus E, Kadioglu A, Esen A, et al. (Turkish Erectile Dysfunction Prevalence Study Group). Prevalence an correlates of erectile dysfunction in Turkey: A Population based Study. Eur Urol 2002; 41: 298-304.

3. American Academy of Sleep Medicine. ICSD-2:

The International Classification of Sleep Disorders.

Diagnostic and Coding Manual, 2nd ed. Westchester, Illinois: AASM, 2005

4. Similowski T, Yan S, Gauthier AP, Macklem PT, Bellemare F. Contractile properties of the human diaphragm during chronic hyperinflation. N Engl J Med 1991; 325: 917-923. 
5. Köktürk O, Tatlıcıŏlu T, Kemaloğlu Y, Firat H, 17. Hirshkowitz M, Karacan I, Gurakar A, Wil-

Cetin N. Habituel horlaması olan olgularda obstrüktif liams RL. Hypertension, erectile dysfunction and sleep apne sendromu prevelansı. Tüberküloz ve Toraks 1997; 45;1: 7-11. occult sleep apnea. Sleep 1989; 12: 223-232 6. Somers VK, Dyken ME, Clary MP, Abboud FM. roy K, Fry JM. Problems in the interpretation of Sympathetic neural mechanisms in obstructive sleep nocturnal penile tumescence studies: disruptions of apnea. J Clin Invest 1995; 96: 1897-1904.

7. Pugh LG.Physiological and medical aspects of 598.

the Himalayan scientific and mountaineering expedi- 19. Aserinsky E, Kleitman N. Regularly occurring tion, 1960-61. BMJ 1962; 2: 621-627.

8. Wolf J, Lewicka J, Narkiewicz K. Obstructive sleep

apnea: an update on mechanisms and cardiovascula consequences. Nutr Metab Cardiovasc Dis 2007; 17: 233-240.

9. Perimenis P, Konstantinopoulos A, Karkoulias K Markou S, Perimeni P, Spyropoulos K.. Sildenafil combined with continous positive airway pressure for treatment of erectile dysfunction in men with obstructive sleep apnea. Int Urol Nephrol 2007; 39:547-552.

10. Taskin U, Yigit O, Acioglu E, Aricigil M, Toktas $\mathrm{G}$ and Guzelhan Y. Erectile dysfunction in severe sleep apnea patients and response to CPAP. Int J Impot Res 2010; 22: 134-139.

11. Shin HW, Park JH, Park JW, Rhee CS, Lee CH, Mi YG, et al. Effects of surgical versus nonsurgical therapy on erectile dysfunction and quality of life in obstructive sleep apnea syndrome: a pilot study. J Sex Med 2013; 10: 2053-9.

12. Budweiser S, Luigart R, Jorres RA, Kollert F, Kleemann Y, Wieland WF, et al. Long- term changes of sex-

ual function in men with obstructive sleep apnea after initiation of continuous positive airway pressure. J Sex Med 2013; 10: 524-31.

13. Epstein LJ1, Kristo D, Strollo PJ Jr, Friedman N, Malhotra A, Patil SP, et al. Clinical Guideline for the Evaluation, Management and Long-term Care of $\mathrm{Ob}$ structive Sleep Apnea in Adults JClin Sleep Med 2009, 5: 263-276.

14. Guilleminault C, Eldridge FL, Tilkian A, Simmon FB, Dement WC. Sleep apnea syndrome due to upper airway obstruction: a review of 25 cases. Arch Intern Med 1977; 137: 296-300.

15. Fanfulla F, Malaguti S, Montagna T, Salvini S, Bruschi $\mathrm{C}$, Crotti $\mathrm{P}$, et al. Erectile dysfunction in men with obstructive sleep apnea: an early sign of nerve involvement. Sleep 2000; 23: 775-781.

16. Guilleminault C. Clinical features and evaluations of obstructive sleep apnea. In: Kryger Meir H, Roth Thomas, Dement William C, editors. Principle and practice of sleep medicine. 2nd ed. Philadelphia, PA: WB Saunders; 1994

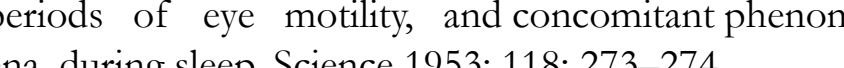

20. Grunstein RR, Handelseman DJ, Lawrence SJ, Blackwell C, Caterson ID, Sullivan CE. Neuroendocrine dysfunction in sleep apnea syndrome: reversal by nasal continuous positive airway pressure. J

21. Grunstein RR. Endocrine and metabolic disturbance in obstructive sleep apnea. In: Sauders NA, Sullivan CE, editors. Sleep and breathing. New York: Dekker; 1994. p.449-492.

22. Gonçalves MA, Guilleminault C, Ramos E, Palha A, Paiva T. Erectile Dysfunction, Obstructive Sleep Apnea Syndrome And Nasal CPAP Treatment. Sleep Med 2005; 6:333-339. Gourgoulianis KI. Reactive oxygen metabolites (ROMs) nea patients. Sleep Breath 2003; 7:105-110.

24. Andersen ML, Santos-Silva R, Bittencourt LR, Tufik S. Prevalence Of Erectile Dysfunction Complaints Associated With Sleep Disturbances in Sao Pauo, Brazil: A Population-Based Survey. Sleep Med 2010 11: 1019-1024.

5. Hirshkowitz M, Karacan I, Arcasoy MO, Acik G, Narter EM, Williams RL.Prevalence of sleep apnea in men with erectile dysfunction. Urology 1990; 36: 232-234.

26. Schiavi RC, Mandeli J, Schreiner-Engel P, Chamber A. Aging sleep disorders, and male sexual function. Biol Psychiatry 1991; 30: 15-24.

27. Seftal AD, Strohl KP, Loye TL, Bayard D, Kres J, Netzer NC. Erectile dysfunction and symptoms of sleep disorders. Sleep 2002; 25: 643-647.

28. Margel D, Cohen M, Livne PM, Pillar G. Severe, but not mild, obstructive sleep apnea syndrome is associated with erectile dysfunction. Urology 2004; 63: $545-549$.

29. Perimenis P, Karkoulias K, Konstantinopoulos A, Perimeni P, Katsenis G, Athanasopoulos $A$, et al Sidenafil versus continuous positive airway pressure for erectile dysfunction in men with obstrucClin Endocrinol Metab 1989; 68: 352-358.

23. Christou K, Markoulis N, Moulas AN, Pastaka C as an index of oxidative stress in obstructive sleep ap- tive sleep apnea: a comparative study of their efficacy and safety and the patients satisfaction with treatment. Asian J Androl 2007; 9: 259-264.

30. Margel D, Tal R, Livne PM, Pillar G. Predictors Of Erectile Function Improvement In Obstructive Sleep Apnea Patients With Long-Term CPAP Treatment. Int J Impot Res 2005;17:186-190.

31. Gambineri A, Pelusi C Pasquali R. Testosterone levels in obese male patients with obstructive sleep apnea syndrome: relation to oxygen desaturation, bod weight, fat distribution and the metabolic parameters. J Endocrinol Invest 2003; 26: 493-498.

32. Rosen RC, Cappelleri JC, Gendrano N. The international index of erectile function (IIEF): a state-of-thescience review. Int J Impot Res 2002; 14: 226-244.

33. Aalto AM, Elovainio M, Kivimaki M, Uutela A, eral Health Questionnaire as measures of depression in the general population: a validation study using the Composite International Diagnostic Interview as the gold standard. Psychiatry Res 2012; 197: 163-171. 